\title{
Outcome of Pregnancy in Chromosomally Normal Foetus with Increased Nuchal Translucency
}

\author{
Ranjit $\mathrm{S}^{\mathrm{a}}$, Carol $\mathrm{P}^{\mathrm{b}}$, Kellie $\mathrm{C}^{\mathrm{b}}$,Pauline $\mathrm{M}^{\mathrm{b}}$, Renuka $\mathrm{S}^{\mathrm{b}}$ \\ ${ }^{a}$ Department of Obstetrics \& Gynecology, Hospital Seberang Jaya,Penang \\ ${ }^{b}$ Department of Maternal Fetal Medicine, Royal Brisbane Womens Hospital,Brisbane
}

\begin{abstract}
Objective: The aim of this study is to evaluate the outcome of pregnancy in prenatal and postnatal period of pregnancy complicated with thick nuchal translucency but normal karyotype. Methods: This is a retrospective study of 119 singleton pregnancies with increased NT (NT $\geq 2.5 \mathrm{~mm}$ ) but a normal karyotype over a 3 year period. The records of ultrasound at 18-20 and 25-26 weeks', antenatal and postnatal details were reviewed. The developmental and health outcomes of the surviving children were obtained through telephone conversation with the family. Adverse outcome such as miscarriages, termination of pregnancy, intrauterine death, structural anomalies and neurodevelopment delay were analysed. Results: Out of 119 foetuses with increased NT but normal karyotype, $11.8 \%$ of pregnancies ended with miscarriages, termination of pregnancy and intrauterine death. $89.9 \%$ foetuses were structurally normal. $12.9 \%$ presented with structural anomalies in the second-trimester ultrasound scan. $81.8 \%$ showed major malformations, out of which $44 \%$ consisted of heart defects. $1 \%$ of foetuses were syndromic and $1.9 \%$ had developmental delay. $96.8 \%$ of foetuses with NT equal to or greater than the $95^{\text {th }}$ percentile $(3.4 \mathrm{~mm})$ and $80 \%$ with NT equal to or greater than the 99 percentile $(5.5 \mathrm{~mm})$ had a normal outcome. $50 \%$ of foetuses with thickened nuchal fold had a poor outcome. Postnatal follow-up was established for all infants and toddlers, and abnormalities were observed in $5.6 \%$ of them. Chances of having a live and healthy infant decreases with increased NT, corresponding to $80 \%$ for NT equal to or greater than $5.5 \mathrm{~mm}$. Conclusion: We have provided data that may help in the counselling of parents and increasing their confidence on a favourable pregnancy outcome. In cases with increased nuchal translucency but normal karyotype, the chances of normal pregnancy success rate is $89.9 \%$. Parents can be reassured that thickened nuchal translucency with a normal karyotype and normal targeted ultrasound between 20-22 weeks gestation, the risk of adverse perinatal outcome and postnatal developmental delay is not increased in comparison with that of the general population. This seems to be the case for all degrees of increased nuchal translucency.
\end{abstract}

KEYWORDS: Prenatal diagnosis, foetal monitoring, pregnancy, prenatal care, ultrasound

\section{INTRODUCTION}

Nuchal translucency (NT) measurement is an excellent screening test for foetal chromosomal abnormalities as well as congenital heart defects. ${ }^{1}$ It is the transient subcutaneous fluid collection in the foetal neck seen via ultrasound scan, between 11-14 weeks of gestation. ${ }^{1}$

NT together with maternal age and biochemical markers ie pregnancy-associated plasma protein-A

Corresponding Author:

Dr Ranjit Singh Bhagwan Singh

Hospital Seberang Jaya,

Obstetrics \& Gynaecology

Jalan Hussein Onn, Prai,

Georgetown, 13700, Malaysia

Tel :+6043827333 / 60194426699

Email: ranjitsg13@gmail.com
(PAPP-A) and free beta-human chorionic gonadotrophin (B-hCG), has a sensitivity of $90 \%$ with a false positive rate of $5 \%$ to detect trisomies (T13, T18, T21 and Turners Syndrome). ${ }^{1-4}$

All pregnancies with normal karyotype and increased NT are offered detailed ultrasound at 18-20 weeks to exclude structural anomalies that are associated with trisomies. ${ }^{9}$

Increased NT with a normal karyotype leaves patients and her treating clinician in further dilemma. Extensive counselling from clinician in terms of developmental delay in early childhood and adverse pregnancy outcomes such as miscarriage, major fetal anomalies and fetal death are needed. ${ }^{5-8}$

Bilardo et al in 2007 concluded, that if the morphology scan at 20 weeks is normal, parents can be reassured of a favourable outcome. 9 The aim of this study is to evaluate the outcome of pregnancies 
with increased NT and normal karyotype with respect to their short term infant and toddler growth and neonatal morbidities. This will allow practitioners to utilize this information to better inform patients about the application of NT screening.

\section{MATERIAL AND METHODS}

There were 249 cases with NT measurement more than $2.5 \mathrm{~mm}, 6.0 \%$ declined invasive testing and $33.3 \%$ became low risk after combination with first trimester blood screening (PAPP-A and beta hCG blood testing) hence not requiring invasive testing. Increased NT referred to foetuses with NT more than $2.5 \mathrm{~mm}$ above $95^{\text {th }}$ centile. Therefore the number of patients subjected to karyotyping was 146 of which 119 patients had normal karyotype and were included in the study.

Royal Brisbane Women Hospital (RBWH) is a tertiary Maternal Fetal Medicine referral centre in Brisbane, Australia. Patients found to have increased NT $(\geq 2.5 \mathrm{~mm})$ at the first-trimester ultrasound scan in our hospital as well as other local hospitals in the catchment areas were referred for a detailed firsttrimester anomaly ultrasound scan, blood investigations (PAPP-A and free B-hCG), counseling and invasive tests for foetal karyotyping. Blood investigations ie PAPP-A and free B-hCG were done in all cases with increased NT.

This is a retrospective study carried out over 3 years from September 2009 to September 2012. There were 119 patients with increased NT and normal karyotype during our study period. We included all singleton pregnancies in our study. We excluded foetuses with chromosomal abnormalities. Based on advice from the local Human Research Ethics Committee of Royal Brisbane Women Hospital, it was concluded that formal Ethics approval was not required as it constituted a retrospective review study.

NT measurement was performed using the criteria recommended by Fetal Medicine Foundation (FMF) guidelines by qualified and FMF accredited sonographers using high-resolution equipment (Voluson Pro, GE Healthcare). Increased NT is defined as a measurement above the $95^{\text {th }}$ centile for the normal range, which is above $2.5 \mathrm{~mm}$. In pregnancies with increased NT and normal karyotype we recommend follow-up ultrasound scans at 18-20 and 25-26 weeks gestation. Structural heart defects detected during morphology scans were referred for specialist foetal echocardiography between 20-24weeks.

The follow-up ultrasound scans were performed at the RBWH in the majority of cases. All patients were managed to be contacted though some women opted to have follow up at their local hospitals. Karyotype results and details on pregnancy outcomes were retrieved from the computer database. Records on pregnancy outcome were obtained from the maternity units' nursery records, the general practitioners or the mothers themselves. Details on follow-up ultrasound scans were obtained from the RBWH database or the obstetric ultrasound units if the follow-up scans were carried out locally. All babies were examined at birth by neonatologist or paediatrician.

The outcome of babies were reviewed from their discharge summaries or asked by telephone interviews with parents, general practitioners, or the paediatrician. The follow-up period at the time of telephone interviews ranged between 5 months to 3 years. The developmental milestones of the child were obtained via telephone interview with both parents and their general practitioners in every single case. The prevalence of pregnancy outcome including miscarriage, hydrops fetalis, intrauterine death, foetal structural abnormalities diagnosed before or after delivery, termination of pregnancy including indicated or maternal request, presence of any early developmental delay and genetic syndrome were noted and documented. An adverse pregnancy outcome was considered when there was natural loss of the prenatal conceptus or neonatal death. Spontaneous abortion is a non-viable pregnancy before the $20^{\text {th }}$ week of gestation and intrauterine fetal death is beyond $20^{\text {th }}$ week of pregnancy. $^{11}$

\section{RESULTS}

Total number of deliveries over this study period $(1 / 9 / 2009$ till $30 / 9 / 2012)$ of 3 years at RBWH was 13,983 and the total NT scans done during this period was 3852. The cut off point for increased NT was taken as $>2.5 \mathrm{~mm}$. From the sampled, 249 fetuses with increased NT, 15 declined invasive procedure and 83 became low risk when evaluated in combination with first trimester blood screening; hence these were excluded from the study. 5 patients with multiple pregnancies were also excluded. Of the 146 remaining cases, 119 had normal karyotypes with mean maternal age of 32.3 years (Standard Deviation of $32.3+5.77$ ) and mean NT of $3.71 \mathrm{~mm}$ (Standard Deviation of $3.71 \pm 1.23$ ). There was male preponderance in karyotype number being 2:1 (M:F) ratio. Foetal karyotyping was carried out by means of Chorionic villous sampling (CVS) in 55 pregnancies and amniocentesis in 62 pregnancies. $10.1 \%$ ended up with pregnancy loss (miscarriage, intrauterine death and termination of pregnancy).

Morphological ultrasound scan was done in 116 cases as 2 patients had miscarriage and one had intrauterine death. In $97.5 \%$ of the cases, second trimester ultrasound scans were performed, of which $87.1 \%$ did not show abnormal findings.

From the 15 cases with abnormal morphological findings, 12 cases had major malformations, and 3 cases had minor defects as in Table 1 and 2. 
Table 1. List of fetal with structural anomalies $(\mathrm{N}=$ total number of cases)

\begin{tabular}{ll}
\hline \multicolumn{1}{c}{ Major Defects $(\mathrm{N}=12)$} & \multicolumn{1}{c}{ Minor Defects $(\mathrm{N}=\mathbf{3})$} \\
\hline Fetal Akinesia/ & $\begin{array}{l}\text { Unilateral Multicystic } \\
\text { Dysplastic Kidney } \\
\text { Arthrogryoposis }\end{array}$ \\
Renal agenesis & $\begin{array}{l}\text { Mild ventriculomegaly } \\
\text { Single Umbilical }\end{array}$ \\
Hypoplastic Left & Artery \\
Heart Syndrome(2 cases) & \\
Fetal Hydrops & \\
Pulmonary Atresia, Situs & \\
Inversus & \\
Moderate Ventricular Septal & \\
Defect & \\
Pulmonary Atresia, & \\
Hypoplastic right heart & \\
Limb body wall complex & \\
Short limbs, Cystic Hygroma & \\
Coarctation of aorta \\
Atrial Ventricular Septal \\
Defect, Transposition of \\
Great Vessels
\end{tabular}

Of the 116 foetuses submitted to morphological ultrasound examination at second trimester, the nuchal fold was enlarged in 2 cases

Seven cases were submitted for foetal echocardiography in the prenatal period. Of this total, 3 exhibited normal results, whereas $57.1 \%$ (4/7) showed abnormal echocardiograph findings. The overall pregnancy outcome was known in all cases but $17.7 \%(21 / 119)$ did not carry the pregnancy to full term. $1.7 \%(2 / 119)$ had spontaneous miscarriage, $0.8 \%(1 / 119)$ showed intrauterine fetal death and $7.6 \%$ (9/119) had termination of pregnancy due to various structural anomalies.

Out of the 9 termination of pregnancy, 4 were due to cardiac pathology accounting for $44.4 \%$ delivered prematurely due to various obstetric reasons. In our patient population, the chances of termination of pregnancy, resulting in foetal or neonatal loss, grew proportionally to the increase in NT. However; this risk was more evident when NT was thicker than $3.2 \mathrm{~mm}$. It was also observed that when NT was equal to or greater than $3.6 \mathrm{~mm}$, it was associated with structural malformation or malformation markers (Table 2 and 3 ).

In the postnatal follow-up, the infant's mean age was 19.7 months (standard deviation of $19.7+9.6$ ). Mean birth weight was 3416 grams (standard deviation of $3416 \pm 695.5$ ). A total of 107 babies were submitted to postnatal follow-up, and $5.6 \%$ $(6 / 107)$ had some morphological or functional problem.
Table 2.Anomalies found at 20 weeks ultrasound in increased NT but normal karyotype fetuses

\begin{tabular}{|c|c|c|}
\hline $\begin{array}{l}\text { Nuchal } \\
\text { translucency } \\
\text { thickness at } \\
11-14 \text { weeks } \\
\text { of gestation. } \\
(n=15)\end{array}$ & $\begin{array}{l}\text { Ultrasound findings at } \\
20 \text { weeks with normal } \\
\text { nuchal fold }\end{array}$ & $\begin{array}{l}\text { Ultrasound find- } \\
\text { ings at } 20 \text { weeks } \\
\text { with increased } \\
\text { nuchal fold }\end{array}$ \\
\hline $3.0 \mathrm{~mm}$ & Absent nasal bone & \\
\hline $3.1 \mathrm{~mm}$ & $\begin{array}{l}\text { Unilateral Multicystic } \\
\text { Dysplastic Kidney }\end{array}$ & \\
\hline $3.2 \mathrm{~mm}$ & $\begin{array}{l}\text { Fetal Akinesia/ } \\
\text { Arthrogryoposis } \\
\text { Hypoplastic Left Heart } \\
\text { Syndrome }\end{array}$ & \\
\hline $3.3 \mathrm{~mm}$ & $\begin{array}{l}\text { Renal agenesis, } \\
\text { Hypoplastic Left Heart } \\
\text { Syndrome }\end{array}$ & \\
\hline
\end{tabular}

No abnormalities

$3.5 \mathrm{~mm}$ detected

3.6mm Hypoplastic Left Heart Syndrome

$3.8 \mathrm{~mm}$

Fetal Hydrops

$3.8 \mathrm{~mm}$

Pulmonary Atresia, Situs inversus

$4.1 \mathrm{~mm}$

No

abnormalities detected
$4.1 \mathrm{~mm}$
Moderate Ventricular Septal defect
4.3mm Single Umbilical Artery
4.4mm Pulmonary Atresia, Hypoplastic right heart
$5.9 \mathrm{~mm} \quad$ Limb body wall com- plex

$8.7 \mathrm{~mm}$

Short limbs, Cystic Hygroma

$9.9 \mathrm{~mm} \quad$ Mild ventriculomegaly

All the 107 cases were seen by the paediatrician post -delivery and were being regularly followed-up by their general practitioners. Furthermore both the parent's and the general practitioner were contacted and a telephone interview was held in each and every one of the cases regarding progress of the babies.

Of the 6 babies with morphological/functional problem. Two babies had developmental delay (one with seizure disorder), the other babies had lung oedema but discharged well, Vntricular Septal Defect requiring surgery, ectopia lentis et pupillae (genetic disorder), and cystic nephroma of left kidney respectively. Ectopia lentis et pupillae was noted by paediatrician for suspected ectopic lens, hence referred to ophthalmologist whereby iridodonesis was obvious which was confirmed by gonioscopy and geneticist. 
The chances of having a live born and healthy infant varied according to the measurement of the foetal NT, being inversely related to the thickness of $\mathrm{NT}^{26}$, amounting to $96.8 \%$ when NT was equal to or greater than the $95^{\text {th }}$ percentile up to $3.4 \mathrm{~mm}$ and $80 \%$ live birth and healthy infants when equal to or greater than $5.5 \mathrm{~mm}$ as shown in Table 3.

Table 3: Pregnancy Outcomes of Fetuses with Normal Karyotype and Increased Nuchal Translucency

${ }^{1}$ Significant if $\mathrm{p}<0.05$

\begin{tabular}{|c|c|c|c|c|c|c|c|c|c|}
\hline $\begin{array}{l}\text { Nuchal } \\
\text { Transl. } \\
\text { NT } \\
\text { (mm) }\end{array}$ & $\begin{array}{l}\text { Normal } \\
2^{\text {nd }} \\
\text { Trimester } \\
\text { U/S (N) }\end{array}$ & $\begin{array}{l}\text { Normal } \\
\text { Delivery } \\
(\mathrm{N})\end{array}$ & $\begin{array}{l}\text { Live Births } \\
\text { No Defects } \\
\text { (N) }\end{array}$ & $\begin{array}{c}\text { Adverse } \\
\text { outcome } \\
\text { at } \\
\text { delivery } \\
\text { (N) }\end{array}$ & $\begin{array}{c}\text { Chi } \\
\text { Squared } \\
\text { 1P-value }\end{array}$ & $\begin{array}{c}\text { Structural } \\
\text { Anomalies on } \\
2^{\text {nd }} \text { Trimester } \\
\mathrm{U} / \mathrm{S}(\mathrm{N})\end{array}$ & $\begin{array}{c}\text { Chi- } \\
\text { Squared } \\
{ }^{1} \text { P-value }\end{array}$ & $\begin{array}{l}\text { Live } \\
\text { births } \\
\text { With } \\
\text { defects } \\
\text { (N) }\end{array}$ & $\begin{array}{c}\text { Chi- } \\
\text { Squared } \\
{ }^{1} \text { P-value }\end{array}$ \\
\hline $2.5-3.4$ & $60(92.3 \%)$ & 59 & $60(96.8 \%)$ & 8 & 0.037 & $5(7.7 \%)$ & 0.015 & $2(3.2 \%)$ & 0.230 \\
\hline $3.5-4.4$ & $25(79.4 \%)$ & 26 & $27(90.0 \%)$ & 8 & & $7(20.6 \%)$ & & $3(10.0 \%)$ & \\
\hline $4.5-5.4$ & $\begin{array}{c}10 \\
(100.0 \%)\end{array}$ & 9 & $10(100.0 \%)$ & 1 & & $0(0.0 \%)$ & & $0(0.0 \%)$ & \\
\hline$>5.5$ & $4(57.1 \%)$ & 4 & $4(80.0 \%)$ & 4 & & $3(42.9 \%)$ & & $1(20.0 \%)$ & \\
\hline Total & $\begin{array}{c}101 \\
(87.1 \%)\end{array}$ & 98 & $101(94.4 \%)$ & 21 & & $15(12.9 \%)$ & & $6(5.6 \%)$ & \\
\hline
\end{tabular}

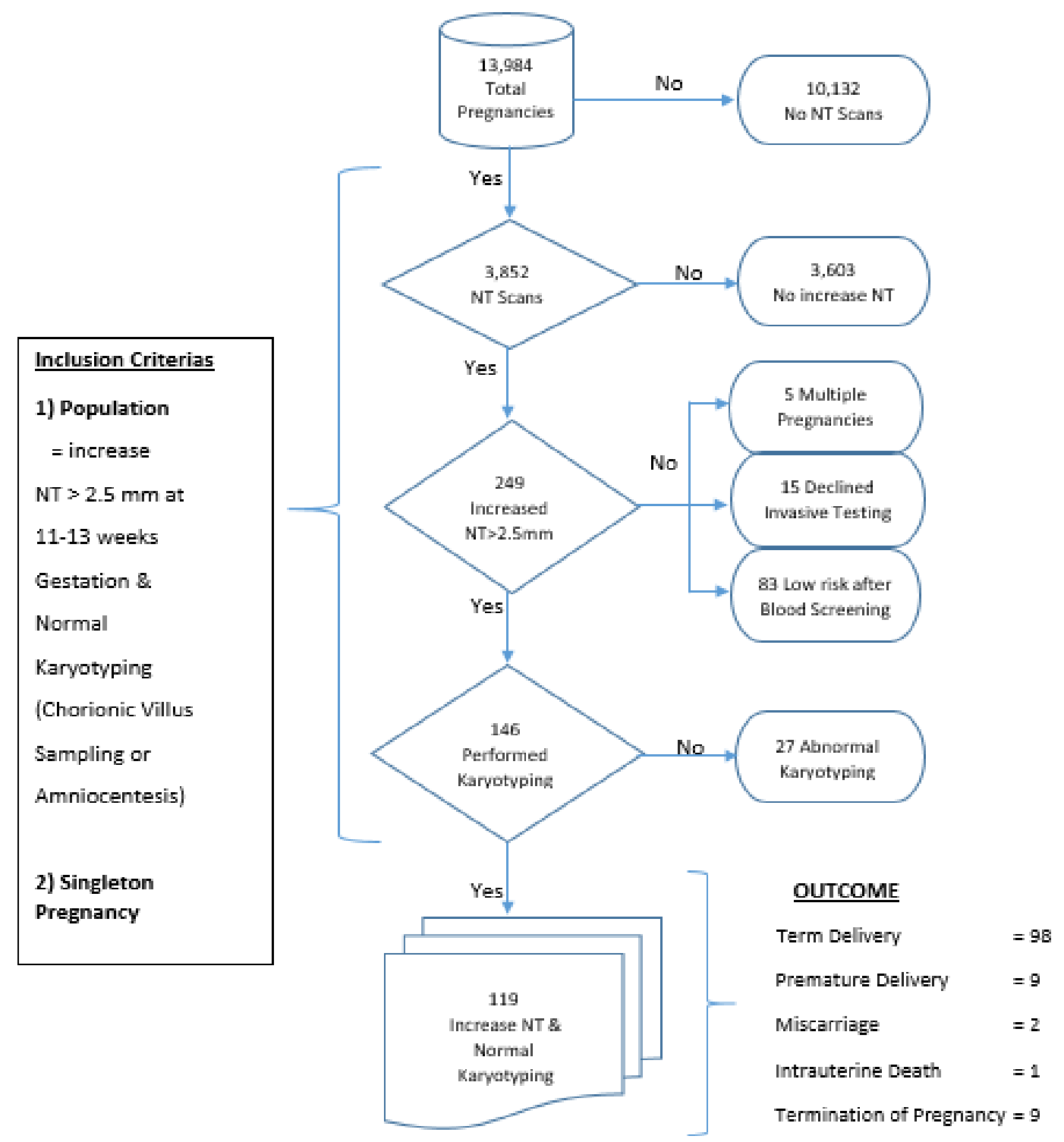

Figure 1: Study Flow Chart 


\section{DISCUSSION}

It is well accepted that increased NT is a nonspecific finding of genetic or structural anomalies. Commonly associated foetal structural anomalies with increased NT but normal karyotypes are major cardiac defects, exomphalos, congenital diaphragmatic hernia, orofacial and skeletal defects. In our series, the prenatal detection rates for structural anomalies were $12.9 \%$, of which $82 \%$ major malformations. Of these major malformations, $44.4 \%$ heart defects. This study detected $3.8 \%$ of congenital heart defects including cases which were terminated, while the general population incidence being only around $1 \% .^{13}$

The percentage of cardiac defects shown in this study is $1.5 \%$ when the NT was above the $95^{\text {th }}$ centile and $7 \%$ when the NT was above the $99^{\text {th }}$ centile, close/similar to that reported by Hyett et al (1999) viz $2 \%$ and $6 \%$ when NT was above the $95^{\text {th }}$ centile and $99^{\text {th }}$ percentile respectively. ${ }^{14}$ It is proven that NT measurements exceeding the $99^{\text {th }}$ centile are a very strong indication for foetal echocardiography by paediatric cardiologist. In our centre, all cases with slightest index of suspicion of cardiac pathology were referred for specialist foetal echocardiography; hence all of our cases with heart defects were diagnosed during the antenatal period.

Our study showed that an adverse outcome (including miscarriage, foetal demise, termination of pregnancy), foetal structural defects occurred in $21.8 \%$ of karyotypically normal foetuses presenting with NT above the $95^{\text {th }}$ percentile at $11+0$ to $13+6$ weeks. This rates are lower compared to those obtained in cohorts from referral centres such as those reported by Bilardo et al (2007) in Amsterdam and Senat et al (2007) in Paris at 32\% and 39\% respectively but similar to those of unselected pregnancies at $17 \% .^{9,15}$ As previously reported, the prevalence of an adverse outcome was found to increase with NT thickness, from $23 \%$ for NT of 3.5$4.4 \mathrm{~mm}$ to $67 \%$ for NT above $5.5 \mathrm{~mm}$. Similarly, Bilardo et al (2007) reported a frequency of $17 \%$ for an adverse outcome for NT of $3.5-4.4 \mathrm{~mm}$, increasing to $80 \%$ for NT above $6.5 \mathrm{~mm}^{9}$.

In our series, enlarged NT was observed in $1.7 \%$ of foetuses during the second- trimester morphology ultrasound scan. The group with enlarged NT with no other findings in the ultrasound scan showed no anomalies in the prenatal and postnatal follow up.

In our study of 119 chromosomally normal foetuses, we observed a foetal loss rate of $89.2 \%$ and survival rates is only $27.3 \%$ when it is associated with structural malformations. Souka et al (2001), estimate that only one in every three foetuses with NT equal to or greater than $6.5 \mathrm{~mm}$ progresses to a live birth without structural malformation. ${ }^{22}$ Therefore they concluded that pregnancy outcome depends on NT thickness and its association with foetal structural defects. With regards to increased NT and adverse pregnancy, only one study dealt with follow up of live born infants and children after the age of 5 years with a control group ${ }^{15}$. These findings of increased NT in the presence of normal karyotype inevitably cause stress on parents. The fear of nondetectable anomalies induces anxiety and hence a hasty decision for termination of wanted pregnancy. The most worrying aspect that goes undetected via an ultrasound and manifest unexpectedly in the postnatal period is genetic syndrome with neurodevelopmental delay. The incidence of neurodevelopmental delay with or without genetic syndrome in a foetus with increased NT and normal karyotype ranges from 0 to $13 \%$. Comparison between studies becomes difficult as cut-offs of increased NT are different and the length of postnatal follow-ups are different as well.

In our study, only $4.6 \%$ had either functional or morphological anomaly on postnatal follow-up of infants. The rest were normal. Genetic syndromes are associated with increased NT, as reported in previous studies. ${ }^{10}$ In our series, we detected one genetic disorder, Ectopia lentis et pupillae, a disorder not previously associated with increased NT, however the developmental milestones of this child was normal. The frequency of neurodevelopmental delay in our series was comparable $(1.9 \%)$ to larger recent series: $1.2 \%{ }^{24}$ and $1.6 \% .{ }^{9}$ Senat et al (2007) did not show any increased incidence of developmental delay at the age of 2 years as compared with an external group.

The detailed anomaly ultrasound scan has a high sensitivity for detecting structural defects. Therefore, a pregnant woman with a foetus with increased NT and a normal karyotype can be reassured of a favourable pregnancy and developmental outcome after a normal secondtrimester scan.

\section{CONCLUSION}

Chromosomally normal foetuses with increased NT during prenatal care and postnatal follow-up definitely requires attention and further assessment. In our study we have provided data that may help in the counseling of parents and to increase their confidence in a favourable pregnancy outcome. In our study, foetuses with increased NT but normal karyotype, the chances of pregnancy loss was estimated to be $9 \%$, structural anomalies $12.9 \%$, syndromic child $1 \%$, developmental delay $1.9 \%$ and pregnancy success rate $89.9 \%$.

Parents can be reassured with a normal targeted 20-22 week ultrasound scan, the risk of adverse perinatal outcome and postnatal developmental delay is not increased in comparison with that of the general population and this seems to be the case for all degrees of increased NT. 


\section{ACKNOWLEDGEMENTS}

We would like to thank the following personal for their help and contribution to this research:

Dr Leong Chin Tho, Clinical Research Medical Officer, Clinical Research Centre, Hospital Pulau Pinang and Director General of Health Malaysia (for his permission to publish this article.

\section{REFERENCES}

1. Malone, FD, Canick JA, Ball RH, et al.First-trimester or second- trimester screening, or both, for Down's syndrome.N.Engl.J.Med.2005;353(19):2001-2011.

2. Snijders RJM, Noble P, Sebire N, Souka A, Nicolaides $\mathrm{KH}$. UK multicentre project on assessment of risk of trisomy 21 by maternal age and fetal nuchal translucency thickness at 10-14 weeks of gestation.Lancet 1998;351:343-6.

3. Evans MI, Van DH, Nicolaides KH.2007. Nuchal translucency measurements first-trimester screening: the 'price' of inaccuracy. Fetal Diagn. Ther.22(6):401 $-404$.

4. Pandya PP, Kondylios A, Hilbert L, Snijders RJ, Nicolaides KH. Chromosomal defects and outcome in 1015 fetuses with increased nuchal translucency. Ultrasound Obstet Gynecol 1995;5:15-19.

5. Souka AP, von Kaisenberg CS, Hyett JA, Sonek JD, Nicolaides KH. Increased nuchal translucency with normal karyotype. Am J Obstet Gynecol 2005;192:1005-1021.

6. Spencer K, Cowans NJ, Avgidou K, Nicolaides KH. First-trimester ultrasound and biochemical markers of aneuploidy and the prediction of impending fetal death. Ultrasound Obstet Gynecol 2006;28:637-643.

7. Souka AP, Snijders RJM, Novakov A, Soares W, Nicolaides KH. Defects and syndromes in chromosomally normal fetuses with increased nuchal translucency thickness at 10-14 weeks of gestation. Ultrasound Obstet Gynecol 1998;11:391-400.

8. Westin M, Saltvedt S, Almstrom H, Gruneald C, Valentin L. By how much does increased nuchal translucency increase the risk of adverse pregnancy outcome in chromosomally normal fetuses? A study of 16260 fetuses derived from an unselected pregnant population. Ultrasound Obstet Gynecol 2007;29:150-158.

9. Bilardo CM, Muller MA, Pajkrt E, Clur SA, van Zalen MM, Bijlsma EK. Increased nuchal translucency thickness and normal karyotype: time for parental reassurance. Ultrasound Obstet Gynecol 2007;30:1118.

10. Pandya PP, Snijders RJM, Johnson SP, Brizot ML, Nicolaides KH. Screening for fetal trisomies by maternal age and nuchal translucency thickness at 10 -14 weeks of gestation. BJOG 1995;102:957-62.

11. Makrydimas G, Sotiriadis A, loannidis JP. Screening performance of first-trimester nuchal translucency for major cardiac defects:a meta-analysis. Am J Obstet Gynecol 2003;189:1330-5.

12. Bilardo CM, Pajkrt E, Graaf I, Mol BW, Bleker OP. Outcome of fetuses with enlarged nuchal translucency and normal karyotype. Ultrasound Obstet Gynecol. 1998; 11: 401- 6.

13. Hoffman JIE . Incidence of congenital heart disease: I. Postnatal incidence. Pediatr Cardiol. 1995; 16: 103-13.

14. Hyett J, Perdu M, Sharland G, Snijders R, Nicolaides KH. Using fetal nuchal translucency to screen for major congenital cardiac defects at 1014 weeks of gestation: population based cohort study. BMJ 1999; 318: 81-5.

15. Senat MV, De Keersmaecker B, Audibert F, Montcharmont G, Frydman R, Ville Y. Pregnancy outcome in fetuses with increased nuchal translucency and normal karyotype. Prenat Diagn 2002; 22: 345- 349.

16. Timmerman E, Pajkrt E, Maas SM, Bilardo CM. Enlarged nuchal translucency in chromosomally normal fetuses: strong association with orofacial clefts. Ultrasound Obstet Gynecol 2010; 36: 427432.

17. Souka AP, Krampl E, Bakalis S, Heath V, Nicolaides $\mathrm{KH}$. Outcome of pregnancy in chromosomally normal fetuses with increased nuchal translucency in the first trimester. Ultrasound Obstet Gynecol. 2001; 18: 9- 17.

18. Bekker MN. A normal 20 - week scan of a euploid fetus with a history of first-trimester increased nuchal translucency: caution or reassurance? Opin Ultrasound Obstet Gynecol. 2007; 30: 8-10.

19. Senat MV, Bussieres L, Couderc S, Roume J, Rozenbeg P, Bouyer J, et al. Long term outcome of children born after a first-trimester measurement of nuchal translucency at the $99^{\text {th }}$ percentile or greater with normal karyotype: a prospective study. Am J Obstet Gynecol 2007; 196: 53-6.

20. Bilardo CM. Increased nuchal translucency and normal karyotype: coping with uncertainty. Ultrasound Obstet Gynecol 2001; 17: 99- 101.

21. Senat MV, Bussieres L, Couderc S, Roume J, Rozenbeg P, Bouyer J, et al. Long term outcome of children born after a first-trimester measurement of nuchal translucency at the $99^{\text {th }}$ percentile or greater with normal karyotype: a prospective study. Am J Obstet Gynecol 2007; 196: 53-6.

22. Weinans MJ, Kooij L, Muller MA, Bilardo KM, van Lith JM,Tymstra T. A comparison of the impact of screen-positive results obtained from ultrasound and biochemical screening for Down syndrome in the first trimester: a pilot study. Prenat Diagn 2004; 24: 347- 351.

23. Bilardo CM, Muller MA, Pajkrt E. Outcome of fetuses with increased nuchal translucency. Curr Opin Obstet Gynecol 2001; 13: 169-174.

24. Maymon R, Weinraub Z, Herman A. Pregnancy outcome of euploid fetuses with increased nuchal translucency: how bad is the news? J Perinat Med 2005; 33: 191- 198.

25. Lithner $\mathrm{CU}^{1}$, Kublickas $\mathrm{M}^{2}$, Ek $S$ Pregnancy outcome for fetuses with increased nuchal translucency but normal karyotype. J Med Screen. 2016 Mar;23(1):1-6. doi: 
10.1177/0969141315595826. Epub 2015 Jul 20.

26. Bijok J,Ziora-Jakutowicz K,Ilnicka A,Pawlowska B, Jozwiak A, Dangel J, Jakiel G.Incresed Nuchal Translucncy In Chromosomally Normal Fetuses and Pregnancy Outcomes-A retrospective Study.Ginekol Pol 2013 Mar;84(3):172-9

27. Outi Ayras,Minna Tikkanen,Marianne Eronen, Jorma Paavonen, . Increased Nuchal Translucency and Pregnancy Outcome:A retrospective Study of 1063 Consecutive Singleton Pregnancies In A Single Referral Institution.Prenatal diagnosi.Vol 36, Issue 2 , February 2016:199 
